\title{
Sheet metal forming simulation using finite elastoplasticity with mixed isotropic/kinematic hardening
}

\author{
Sami Chatti - Narjess Chtioui \\ Laboratoire de Mécanique (LR 11 ES 36) \\ ENISo, BP 264, Sousse Erriadh, 4023, Tunisie \\ Sami.Chatti@enim.rnu.tn,.chtioui_narjess@yahoo.fr
}

ABSTRACT. A numerical formulation is presented for anisotropic elastoplasticity behavior in finite strain with non-linear isotropic/kinematic hardening model. Non-linear kinematic hardening is modeled by the Lemaitre-Chaboche law with the aim of considering cyclic deformation phenomena. User-defined material subroutines are developed based on Hill's quadratic yield function for both ABAQUS-Explicit (VUMAT) and ABAQUS-Standard (UMAT). For validation purpose, the tension-compression and cyclic shear tests are simulated. Several sheet forming processes including contact, anisotropic plasticity, elastic modulus variation with plastic strain and springback effects are simulated. Numerical results are compared with experimental data.

RÉSUMÉ. Une formulation numérique est présentée pour les modèles élastoplastiques anisotropes en grandes déformations avec de l'écrouissage isotrope/cinématique non linéaire. L'écrouissage cinématique non linéaire est modélisé par le modèle de LemaitreChaboche afin de considérer les chargements cycliques. Des utilitaires numériques ont été développés pour ABAQUS-Explicit (VUMAT) et ABAQUS-Standard (UMAT). Dans un but de validation, les essais de traction et de cisaillement cycliques sont considérés. D'autres simulations plus complexes de mise en forme de tôles sont également réalisées incluant les phénomènes de contact, d'anisotropie, de module élastique variable en fonction de la déformation plastique et de retour élastique. Les résultats numériques sont comparés aux résultats expérimentaux.

KEYWORDS: elastoplasticity, finite strain, FEM, kinematic hardening, springback.

MOTS-CLÉS : éastoplasticité, grande déformation, MEF, écrouissage cinématique, retour élastique.

DOI:10.3166/EJCM.20.427-453 @ 2011 Lavoisier Paris 


\section{Introduction}

Sheet metal forming processes commonly lead to large deformations and rotations which are both non-linear. A material model is important in sheet metal forming simulations in order to accurately predict the final geometry. In particular, sheet anisotropy is an important aspect that has to be considered in order to obtain accurate results (De Sousa et al., 2007; Yoon et al., 2000). In addition, modeling of kinematic hardening is of vital importance when the sheet is submitted to important strain-path changes, such as the traditional bending/unbending due to drawbeads (Taherizadeh et al., 2009). Most rate-independent plastic models have been expressed in terms of ratetype constitutive law, for which the integration scheme has a considerable influence on the convergence of the integration scheme and the accuracy of numerical results. The most popular scheme is based on the predictor-corrector method (return map) during which the stress state is projected on the yield surface (Ortiz et al., 1985; 1986). Finite element methods (FEM) are commonly used to simulate forming processes including springback. Two main integration algorithms have been used to simulate loading (forming)/unloading (springback) stages: implicit/implicit (Laurent et al., 2010), explicit/implicit (Ghaei et al., 2010; Ingarao et al., 2004), and even explicit/explicit (Xu et al., 2004) schemes.

The aim of this work is to develop an incremental scheme (integration algorithm) allowing simulations of metal forming processes, including springback. For this end, material anisotropy, non-linear isotropic/kinematic hardening and large deformations are considered. Also, our objective is to ensure the incremental objectivity and to save the CPU time consuming by considering a modified explicit/implicit incremental formulation. This paper is organized as follows. Section 2 presents a short summary of the important features of an objective elastoplastic constitutive model in large strain including combined non-linear isotropic/kinematic hardening using the Lemaitre-Chaboche model (Lemaître et al., 1985). In particular, the elasticity is described by both hypoelastic and elastic formulations. This latter is reserved to the elastic prediction and especially for springback simulation (Chatti, 2010). In Section 3 is presented the incremental scheme for the integration of the constitutive equations. For validation purpose, the tension-compression test is simulated in Section 4. Cyclic shear test is also investigated in order to check the efficiency and the accuracy of the incremental scheme. Further numerical simulations are carried out as the bulge test and the cylindrical draw cup test. Finally springback is considered by means of the unconstrained cylindrical bending test presented in Numisheet'02 proceeding which involves severe contact conditions. The decrease of the unloading elastic modulus is taken into account in the implemented material model in order to accurately predict springback. Numerical results are compared with published experimental data. The main conclusions and perspectives are stated in Section 5. 


\section{Constitutive equations at finite strains}

The following notations are adopted: $\underline{\mathrm{A}}$ for second order tensor, $\underline{\underline{A}}$ for fourthorder tensor, the symbol ":" between two tensors denotes double contraction (the trace of their product or the usual scalar product of two tensors), the superposed dot denotes the material time derivative and $\otimes$ denotes a tensor product.

\subsection{Kinematical aspects}

In this study the mechanical model takes into account large elastoplastic strains and rotations. The classical multiplicative decomposition of the deformation gradient $\underline{F}=\underline{F}^{\mathrm{e}} \underline{F}^{\mathrm{p}}$ into elastic $\left(\underline{F}^{\mathrm{e}}\right)$ and plastic $\left(\underline{F}^{\mathrm{p}}\right)$ parts is assumed (Mandel, 1971). However, the additive assumption of the strain rate $\underline{D}=\underline{D}^{\mathrm{e}}+\underline{\mathrm{D}}^{\mathrm{p}}$ into elastic $\left(\underline{D}^{\mathrm{e}}\right)$ and plastic $\left(\underline{\mathrm{D}}^{\mathrm{p}}\right)$ parts is also widely used which justified in the case of negligible elastic strain when compared with plastic deformation. It is of importance to notice that models for anisotropic plasticity need an objective formulation. It is well established that the objectivity requirement can be simply obtained by deriving the material model in a Lagrangian configuration obtained from the actual configuration by a rotation $\underline{Q}$ (the so-called rotating frame) which should follows material orientations. In other words, an Eulerian tensor $\underline{\mathrm{A}}$ is expressed in the rotated configuration (with Lagrangian orientations) by the transformation

$$
\underline{\overline{\mathrm{A}}}=\underline{Q}^{\mathrm{T}} \underline{\mathrm{A}} \underline{\mathrm{Q}}
$$

Henceforward, the bar over a tensor indicates that the correspondent tensor is turned by Equation [1]. Notice that this transformation is not applied to a non-(fully) Eulerian tensor, as the elastic and plastic deformation gradients (see Equation [5]). Using the polar decomposition of the elastic and the plastic deformation gradients we obtain the natural intrinsic decomposition

$$
\underline{F}=\underline{F}^{\mathrm{e}} \underline{\mathrm{F}}^{\mathrm{p}}=\underline{\mathrm{V}}^{\mathrm{e}} \underline{\mathrm{R}}^{\mathrm{e}} \underline{\mathrm{R}}^{\mathrm{p}} \underline{\mathrm{U}}^{\mathrm{p}}=\underline{\mathrm{V}}^{\mathrm{e}} \underline{\widetilde{F}}^{\mathrm{p}}
$$

where $\underline{\mathrm{V}}^{\mathrm{e}}$ is the elastic left stretch tensor obtained from the polar decomposition of $\underline{\mathrm{F}}^{\mathrm{e}}, \underline{\mathrm{U}}^{\mathrm{p}}$ is the plastic right stretch tensor obtained from the polar decomposition of $\underline{\mathrm{F}}^{\mathrm{p}}, \underline{\mathrm{R}}^{\mathrm{e}}$ and $\underline{\mathrm{R}}^{\mathrm{p}}$ are, respectively, the elastic and plastic rotations, and $\widetilde{\mathrm{F}}^{\mathrm{p}}$ is introduced to define the stress free configuration (configuration obtained by unloading without rotation). A more general decomposition, called multiplicative decomposition in rotating frame, is adopted (Sidoroff and Dogui, 2001; Badreddine et al., 2010) and given by 


$$
\underline{\mathrm{F}}=\underline{\mathrm{V}}^{\mathrm{e}} \underline{\mathrm{Q}}^{\mathrm{p}}=\underline{\mathrm{Q}}^{\mathrm{V}} \underline{\overline{\mathrm{F}}}^{\mathrm{e}} \overline{\overline{\mathrm{p}}}^{\mathrm{p}}=\underline{\overline{\mathrm{F}}}^{\mathrm{e}} \overline{\mathrm{F}}^{\mathrm{p}}
$$

where $\overline{\mathrm{F}}^{\mathrm{p}}$ is the rotated plastic deformation gradient. Notice that the decomposition [2] leads to the so-called decomposition in the plastic proper rotating frame defined by

$$
\underline{\mathrm{Q}}=\underline{\mathrm{R}}^{\mathrm{e}} \underline{\mathrm{R}}^{\mathrm{p}} ; \underline{\overline{\mathrm{F}}}^{\mathrm{p}}=\underline{\mathrm{U}}^{\mathrm{p}}
$$

From Equations [2] and [3], one can found that

$$
\underline{\overline{\mathrm{F}}}^{\mathrm{p}}=\underline{\mathrm{Q}}^{\mathrm{T}} \underline{\widetilde{\mathrm{F}}}^{\mathrm{p}} ; \overline{\overline{\mathrm{F}}}^{\mathrm{e}}=\underline{\mathrm{V}}^{\mathrm{e}} \underline{\mathrm{Q}}
$$

Using Equation [3], the evolution of the (plastic) rotating frame is derived as

$$
\underline{\mathrm{Q}}=\underline{\widetilde{\mathrm{W}}}^{\mathrm{p}} \underline{\mathrm{Q}}-\underline{\mathrm{Q}}^{\mathrm{W}}
$$

where $\underline{\overline{\mathrm{W}}}^{\mathrm{p}}$ and $\underline{\mathrm{W}}^{\mathrm{p}}$ are the plastic spin tensors relative to $\underline{\overline{\mathrm{F}}}^{\mathrm{p}}$ and $\underline{\widetilde{\mathrm{F}}}^{\mathrm{p}}$, respectively, as

$$
\underline{\overline{\mathrm{W}}}^{\mathrm{P}}=\left[\dot{\overline{\mathrm{F}}}^{\mathrm{p}} \underline{\overline{\mathrm{F}}}^{\mathrm{p}^{-1}}\right]^{\mathrm{A}}, \underline{\widetilde{\mathrm{W}}}^{\mathrm{P}}=\left[\underline{\dot{\mathrm{F}}} \underline{\widetilde{\mathrm{F}}}^{\mathrm{p}^{-1}}\right]^{\mathrm{A}}
$$

where the subscript ' $\mathrm{A}$ ' denotes the antisymmetric part of the tensor. The rotated plastic velocity gradient is given by

$$
\underline{\overline{\mathrm{L}}}^{\mathrm{p}}=\underline{\overline{\mathrm{F}}}^{\mathrm{p}} \underline{\overline{\mathrm{F}}}^{\mathrm{p}^{-1}}=\underline{\overline{\mathrm{D}}}^{\mathrm{P}}+\underline{\overline{\mathrm{W}}}^{\mathrm{P}}
$$

where $\overline{\mathrm{D}}^{\mathrm{p}}$ is the symmetric part of the rotated plastic velocity gradient. Notice that the rotating frame should accurately follow the material axes (orientations). As a consequence, the rotating frame evolution is an essential component of the constitutive model. We assume therefore a kinematic definition of the rotating frame in which

$$
\underline{\overline{\mathrm{W}}}^{\mathrm{p}}=\underline{\underline{\mathrm{K}}}\left(\underline{\widetilde{\mathrm{V}}}^{\mathrm{p}}\right): \underline{\overline{\mathrm{D}}}^{\mathrm{p}}
$$

where $\underline{\underline{K}}$ is a fourth order anti-symmetric tensor. Note that the corotational plastic rotating frame is given by the choice of $\underline{\underline{K}}=\underline{\underline{0}}$ and written as

$$
\underline{\mathrm{Q}} \underline{\mathrm{Q}}^{\mathrm{T}}=\underline{\widetilde{\mathrm{W}}}^{\mathrm{p}}
$$

where, the plastic proper rotating frame is given in Equation [4]. 
Our interest is on the simulations of sheet metal forming processes in which the elastic strain is negligible when compared with the plastic deformation. In this case, it can be shown that the plastic and the total rotating frames are almost the same:

$$
\underline{\mathrm{Q}}^{\mathrm{T}}=\underline{\widetilde{\mathrm{W}}}^{\mathrm{P}} \approx \underline{\mathrm{W}}
$$

Also, it was established (see for example Dogui, 1988) that the choice of a rotating frame has an effect only for tests that allow important rotations of material directions as in shear (or torsion) test with large shear amount (more than $100 \%$ of deformation). It is clear that such amount of deformation cannot be reached in the most of sheet metal forming processes. As a result, the (total) corotationnel rotating frame is chosen because the integration of the differentiel Equation [10] can be simply obtained as it will be shown below.

\subsection{Elastoplastic constitutive equations}

As mentioned above, in order to ensure the objectivity requirement, it is sufficient that tensors used in the constitutive equations have to be written in a rotated configuration (according to Equation [1]). We assume therefore the following constitutive equations for anisotropic elastoplastic behavior in finite strain:

- Elastic law

$$
\bar{\tau}=\underline{\underline{C}}^{\mathrm{e}}: \operatorname{Ln}\left(\underline{\overline{\mathrm{V}}}^{\mathrm{e}}\right)=\underline{\underline{C}}^{\mathrm{e}}: \underline{\bar{\varepsilon}}^{\mathrm{e}}
$$

where $\underline{\tau}$ is the Cauchy stress tensor, $\underline{\varepsilon}^{\mathrm{e}}$ is the logarithmic strain and $\underline{\underline{C}}^{\mathrm{e}}$ is the fourth-order isotropic elastic moduli tensor which can be written as:

$$
\underline{\underline{C}}^{\mathrm{e}}=2 \underline{\underline{\mathrm{I}}}+\left(\mathrm{k}-\frac{2}{3} \mathrm{G}\right) \underline{\mathrm{I}} \otimes \underline{\mathrm{I}}
$$

where $I$ and $I$ are respectively the second and fourth-order unity tensors, $G$ is the shear modulus and $\mathrm{k}$ is the bulk modulus.

- Hypoelastic law

$$
\underline{\bar{\tau}}=\underline{\mathrm{C}}^{\mathrm{e}}: \underline{\overline{\mathrm{D}}}^{\mathrm{e}}=\underline{\mathrm{C}}^{\mathrm{e}}:\left(\overline{\mathrm{D}}-\underline{\overline{\mathrm{D}}}^{\mathrm{p}}\right)
$$

It is of importance to notice that the two elasticity formulations are introduced for the following reasons:

- The hypoelasticity formulation [13] is the widely used in FE codes especially the classical Jaumann derivative. Perhaps the most obvious is that it is the simplest 
stress rate to calculate (leads to similar form as in small strains). It should be noticed that this formulation is habitually justified in the case of small elastic strain (Badreddine et al., 2010). This formulation will be used in the simulations of forming processes (loading). This law is written in a derivative form and must be integrated using an integration scheme and an interpolation path even in elastic evolution. These numerical treatments lead naturally to numerical errors.

- However, the need of an integration algorithm is entirely bypassed when using the elastic law [11] and gives a correct solution in elastic evolution. This law will be used in springback simulation (Chatti, 2010) and also in elastic predictor step.

- Plastic law

$$
\overline{\bar{D}}^{\mathrm{P}}=\lambda \frac{\partial \mathrm{g}(\overline{\bar{\tau}}, \underline{\overline{\mathrm{X}}})}{\partial \underline{\bar{\tau}}}=\lambda \underline{\bar{N}}
$$

where $\overline{\mathrm{N}}$ is normal to the yield function at the current stress point and $\lambda$ is the plastic multiplier which is nonnegative.

- Kinematic law

$$
\underline{\overline{\mathrm{X}}}=\mathrm{K} \underline{\overline{\mathrm{D}}}^{\mathrm{p}}-\lambda \gamma \underline{\overline{\mathrm{X}}}
$$

where $\underline{\bar{X}}$ is a tensorial internal variable (back-stress tensor) describing the kinematic hardening, $\gamma$ characterizes the rate of approaching the saturation state and the ratio $\mathrm{K} / \gamma$ provides the saturation value.

- Yield function

$$
\mathrm{f}(\overline{\bar{\tau}}, \underline{\bar{X}}, \mathrm{p})=\mathrm{g}(\overline{\bar{\tau}}, \underline{\bar{X}})-\mathrm{R}(\mathrm{p})=0
$$

where $\mathrm{p}$ is an internal scalar variable $(\dot{p}=\lambda)$ and $\mathrm{R}$ represents the isotropic hardening stress that defines the size of the yield surface. It is commonly represented by the Swift law given by

$$
\mathrm{R}(\mathrm{p})=\mathrm{C}\left(\varepsilon_{0}+\mathrm{p}\right)^{\mathrm{n}}
$$

Whereas, for materials that exhibit some saturation of flow stress, the Voce law is commonly used

$$
R(p)=\sigma_{0}+Q\left(1-e^{-b p}\right)
$$

where $\sigma_{0}, \mathrm{Q}$ and $\mathrm{b}$ or $\varepsilon_{0}, \mathrm{C}$ and $\mathrm{n}$ are material constants. This study is limited to the orthotropic Hill's 1948 law written as 


$$
\mathrm{g}(\underline{\bar{\tau}}, \underline{\bar{X}})=\sqrt{(\overline{\bar{\tau}}-\underline{\bar{X}}): \underline{\underline{H}}:(\underline{\bar{\tau}}-\underline{\bar{X}})}
$$

where $\underline{\underline{H}}$ is a fourth-order tensor which takes the symmetry of the material into account. In the case of the Von-Mises function, it becomes the identity forth-order tensor. The Hill's stress potential is expressed in the orthotropic axes as

$$
g(\tau)=\sqrt{\begin{array}{l}
F\left(\tau_{22}-\tau_{33}\right)^{2}+\mathrm{G}\left(\tau_{33}-\tau_{11}\right)^{2}+ \\
\mathrm{H}\left(\tau_{11}-\tau_{22}\right)^{2}+2 \mathrm{~L} \tau_{23}^{2}+2 \mathrm{M} \tau_{31}^{2}+2 \mathrm{~N} \tau_{12}^{2}
\end{array}}
$$

where F, G, H, L, M and N are material constants obtained by experimental tests of the material in different directions. Note here that 1,2 and 3 are the material Cartesian coordinates aligned with the rolling, transverse and thickness directions, respectively. Consequently, the normal to the yield stress $\underline{\bar{N}}$ is expressed by

$$
\underline{\bar{N}}=\frac{\underline{\underline{H}}:(\bar{\tau}-\underline{\bar{X}})}{R(p)}
$$

In elastoplastic process, the following cases can happen

- Elastic process for $\lambda=0$ and $\mathrm{f}<0$

- Plastic-elastic unloading for $\lambda=0, \mathrm{f}=0$ and $\dot{\mathrm{f}}<0$

- Plastic loading for $\lambda>0, f=0$ and $\dot{f}=0$ (consistency condition)

These cases can be resumed by the Kuhn-Tucker conditions:

$\lambda \geq 0, \mathrm{f} \leq 0, \lambda \mathrm{f}=0$ and $\lambda \dot{\mathrm{f}}=0$.

In order to solve the global finite element equilibrium equation, it is important to obtain the expression of the elastoplastic tangent modulus. The consistency condition applied to Equation [16] leads to

$$
\mathrm{df}=\frac{\partial \mathrm{g}}{\partial \underline{\bar{\tau}}}: \mathrm{d} \bar{\tau}+\frac{\partial \mathrm{g}}{\partial \underline{\bar{X}}}: \mathrm{d} \underline{\bar{X}}-\frac{\partial \mathrm{R}}{\partial \mathrm{p}} \mathrm{dp}=0
$$

Substituting of Equation [14] into Equation [13] provides

$$
\mathrm{d} \overline{\bar{\tau}}=\underline{\underline{C}}^{\mathrm{e}}:\left(\underline{\operatorname{Ddt}}-\mathrm{dp} \frac{\partial \mathrm{g}}{\partial \bar{\tau}}\right)
$$

Substitution of Equations [15] and [23] into Equation [22] yields 


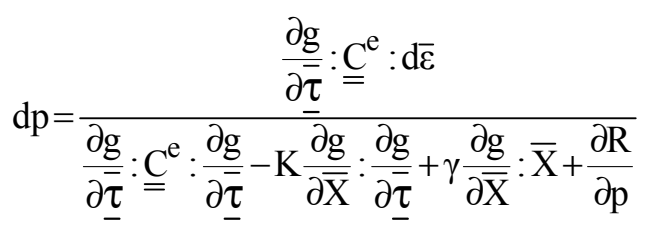

where $\mathrm{d} \underline{\varepsilon}=\underline{\text { Ddt }}$. By Substituting of Equation [24] into Equation [13], the elastoplastic tangent modulus is derived

$$
\frac{\partial \bar{\tau}}{\partial \underline{\bar{\varepsilon}}}=\underline{C}^{\mathrm{ep}}=\underline{\underline{C}}^{\mathrm{e}}-\frac{\left(\underline{\underline{C}}^{\mathrm{e}}: \frac{\partial \mathrm{g}}{\partial \bar{\tau}}\right) \otimes\left(\frac{\partial \mathrm{g}}{\partial \overline{\bar{\tau}}}: \underline{\underline{C}}^{\mathrm{e}}\right)}{\frac{\partial \mathrm{g}}{\partial \underline{\bar{\tau}}}: \underline{\mathrm{C}}^{\mathrm{e}}: \frac{\partial \mathrm{g}}{\partial \underline{\bar{\tau}}}-\mathrm{K} \frac{\partial \mathrm{g}}{\partial \overline{\mathrm{X}}}: \frac{\partial \mathrm{g}}{\partial \underline{\bar{\tau}}}+\gamma \frac{\partial \mathrm{g}}{\partial \overline{\mathrm{X}}}: \overline{\mathrm{X}}+\frac{\partial \mathrm{R}}{\partial \mathrm{p}}}
$$

The derivative of the criteria function [19] gives

$$
\frac{\partial \mathrm{g}}{\partial \underline{\bar{X}}}=-\frac{\partial \mathrm{g}}{\partial \underline{\bar{\tau}}}=-\underline{\bar{N}}
$$

If the tensor $\underline{\underline{C}}^{\mathrm{e}}$ is isotropic [12] and by considering Equation [26], Equations [24] and [25] are respectively rewritten as

$$
\begin{aligned}
& \mathrm{dp}=\frac{2 \mathrm{G} \underline{\bar{N}}: \mathrm{d} \underline{\bar{\varepsilon}}}{(2 \mathrm{G}+\mathrm{K}) \overline{\bar{N}}: \underline{\overline{\mathrm{N}}}-\gamma \underline{\overline{\mathrm{N}}}: \underline{\bar{X}}+\frac{\partial \mathrm{R}}{\partial \mathrm{p}}} \\
& \frac{\partial \overline{\bar{\tau}}}{\partial \underline{\bar{\varepsilon}}}=\underline{\underline{C}}^{\mathrm{ep}}=\underline{\underline{C}}^{\mathrm{e}}-\frac{4 \mathrm{G}^{2} \overline{\bar{N}} \otimes \underline{\bar{N}}}{(2 \mathrm{G}+\mathrm{K}) \underline{\overline{\mathrm{N}}}: \underline{\overline{\mathrm{N}}}-\gamma \underline{\bar{N}}: \underline{\bar{X}}+\frac{\partial \mathrm{R}}{\partial \mathrm{p}}}
\end{aligned}
$$

\section{Numerical aspects}

The FE implementation of such a model requires a numerical integration of the Equations [11-16] over a time increment $\Delta t$, from known state at time $t$ to unknown state at time $t+\Delta t$. The time integration scheme is based on the widely used elasticpredictor/plastic-corrector (return map) using Newton-Raphson iterative algorithm. Here and in the following, the index 0 indicates the time $t$ (the last converged increment) and the index 1 indicates the time $t+\Delta t$. It is assumed therefore that are given the deformation gradients $\underline{\mathrm{F}}_{0}$ and $\underline{\mathrm{F}}_{1}$ and the list of state variables 
$\left\{\underline{\tau}_{0}, \underline{\mathrm{X}}_{0}, \mathrm{p}_{0}, \underline{\mathrm{F}}_{0}^{\mathrm{p}}, \underline{\mathrm{Q}}_{0}\right\}$. Our purpose is to develop a time integration algorithm in order to compute the state $\left\{\underline{\tau}_{1}, \underline{X}_{1}, \mathrm{p}_{1}, \underline{\mathrm{F}}_{1}^{\mathrm{p}}, \underline{\mathrm{Q}}_{1}\right\}$.

\subsection{Elastic prediction}

It is first assumed that the total strain increment is fully elastic then the yield surface equation is used to obtain the equivalent stress. If it is less than, or equal to the yield stress, then the deformation is fully elastic and the trial stress is accepted as the solution. The trial stress state is obtained as follows:

- Obtain the trial elastic deformation gradient: $\underline{\overline{\mathrm{F}}}^{\mathrm{e}}=\underline{\mathrm{F}}_{1} \underline{\mathrm{F}}_{0}^{\mathrm{P}^{-1}}$

- Perform the polar decomposition: $\underline{\overline{\mathrm{F}}}^{\mathrm{e}^{*}}=\underline{\mathrm{Q}}^{*} \underline{\overline{\mathrm{V}}}^{*}$

- Obtain the trial rotated stress tensor: $\underline{\tau}^{*}=\underline{\underline{C}}^{\mathrm{e}}: \operatorname{Ln}\left[\overline{\mathrm{V}}^{\mathrm{e}^{*}}\right]$

- Check for elastic process:

if $\mathrm{f}\left(\underline{\bar{\tau}}^{*}, \underline{\underline{X}}_{0}, \mathrm{p}_{0}\right) \leq 0$ then the process is elastic. Consequently, no evolution of the state variables related to the plastic behavior as

$$
\underline{\mathrm{F}}_{1}^{\mathrm{P}}=\underline{\mathrm{F}}_{0}^{\mathrm{P}} ; \underline{\overline{\mathrm{X}}}_{1}=\underline{\overline{\mathrm{X}}}_{0} ; \mathrm{p}_{1}=\mathrm{p}_{0}
$$

Also, $\underline{\mathrm{Q}}_{1}=\underline{\mathrm{Q}}^{*}$ and $\underline{\mathrm{V}}_{1}^{\mathrm{e}}=\underline{\mathrm{V}}^{\mathrm{e}^{*}}$ and the Cauchy stress is

$$
\underline{\tau}_{1}=\underline{\underline{C}}^{\mathrm{e}}: \operatorname{Ln}\left\lfloor\underline{V}_{1}^{\mathrm{e}}\right\rfloor
$$

The kinematic hardening tensor is performed as

$$
\underline{X}_{1}=\underline{Q}_{1} \underline{X}_{0} \underline{Q}_{1}^{\mathrm{T}}
$$

\subsection{Plastic correction}

If the equivalent stress is higher than the yield stress, a plastic correction is needed by increasing the plastic state. This iteration persists until the updated stress tensor and the state variables verify the yield Equation [16]. In order to update the stress tensor, the hypoelostoplastic law [13] have to be integrated as 


$$
\bar{\tau}_{1}=\bar{\tau}_{0}+\underline{\underline{C}}^{\mathrm{e}}:\left[\int_{\mathrm{t}}^{\mathrm{t}+\Delta \mathrm{t}}\left(\overline{\mathrm{D}}(\tau)-\underline{\bar{D}}^{\mathrm{p}}(\tau)\right) \mathrm{d} \tau\right]
$$

To this end, an interpolation path (to compute $\overline{\mathrm{D}}(\tau), \mathrm{t} \leq \tau \leq \mathrm{t}+\Delta \mathrm{t}$ ) and an integration scheme are needed. It should be noticed that the obtained algorithm must verify the incremental objectivity as defined firstly by Huges et Winget, (1980) and generalized by Sidoroff, (1991). The exponential path (Nagtegaal and Dejong, 1981), assumes that the strain rate is constant over the increment. The following relations can be obtained

$$
\begin{aligned}
& \int_{t}^{\mathrm{t}+\Delta t} \underline{\mathrm{D}}(\tau) \mathrm{d} \tau=\mathrm{Ln}_{-} \\
& \underline{\mathrm{Q}}_{1}=\underline{\mathrm{R}}_{\Delta} \underline{\mathrm{Q}}_{0}
\end{aligned}
$$

where $\underline{\mathrm{F}}_{\Delta}=\underline{\mathrm{R}}_{\Delta} \underline{\mathrm{U}}_{\Delta}$ (polar decomposition). Using the integration parameter $\mathrm{s}$, which can take values between 0 and 1 , the stress tensor is updated as

$$
\underline{\bar{\tau}}_{1}=\overline{\bar{\tau}}_{0}+\underline{\underline{C}}^{\mathrm{e}}:\left[\operatorname{Ln} \underline{U}_{\Delta}-\left((1-\mathrm{s}) \underline{\bar{N}}_{0}^{\mathrm{p}}+\mathrm{s} \underline{\bar{N}}_{1}^{\mathrm{p}}\right) \Delta \mathrm{p}\right]=\underline{\bar{\tau}}^{*}-\underline{\mathrm{C}}^{\mathrm{e}}:\left[(1-\mathrm{s}) \underline{\bar{N}}_{0}^{\mathrm{p}}+\mathrm{s} \underline{\bar{N}}_{1}^{\mathrm{p}}\right] \Delta \mathrm{p}
$$

where $\overline{\mathbf{N}}_{1}=\frac{\partial \mathrm{g}\left(\bar{\tau}_{1}, \overline{\mathrm{X}}_{1}\right)}{\partial \bar{\tau}_{1}}$ presents the normal direction to the yield criterion at the updated stress (radial direction), $\overline{\mathrm{N}}_{0}=\frac{\partial \mathrm{g}\left(\underline{\bar{\tau}}_{0}, \overline{\mathrm{X}}_{0}\right)}{\partial \underline{\bar{\tau}}_{0}}$ presents the explicit direction and $\Delta \mathrm{p}$ is the increment of the scalar internal variable given by

$$
\Delta \mathrm{p}=\mathrm{p}_{1}-\mathrm{p}_{0}
$$

Also, the updated back-stress can be obtained as

$$
\underline{\bar{x}}_{1}=\frac{1}{1+\mathrm{s} \gamma \Delta \mathrm{p}}\left[(1-(1-\mathrm{s}) \gamma \Delta \mathrm{p}) \underline{\bar{X}}_{0}+\mathrm{K} \Delta \mathrm{p}\left((1-\mathrm{s}) \underline{\mathbf{N}}_{0}+\mathrm{s} \underline{\bar{N}}_{1}\right)\right]
$$

Remark that the explicit method is obtained for $s=0$, the radial return method for $\mathrm{s}=1$ and the midpoint method for $\mathrm{s}=0.5$. Ortiz and Popov, (1985) (small strains) and Chatti et al., (2001) (large strains) have studied these methods and they found that:

- The explicit scheme presents convergence problems (not stable).

- Numerical stability increases as the parameter s does.

- Numerical results accuracy decreases as the parameter s increases. 
- The radial return method is the most stable but presents the problem of inaccuracy of the numerical solutions.

- The midpoint scheme has been recommended.

Using the midpoint scheme, Equation [35] is rewritten as

$$
\bar{\tau}_{1}=\underline{\bar{\tau}}^{*}-\underline{\underline{C}}^{\mathrm{e}}:\left[\underline{\mathrm{N}}_{0}+\underline{\overline{\mathrm{N}}}_{1}\right] \Delta \mathrm{p} / 2
$$

and the back-stress is expressed by

$$
\underline{\bar{X}}_{1}=\frac{1}{2+\gamma \Delta \mathrm{p}}\left[(2-\gamma \Delta \mathrm{p}) \underline{\bar{X}}_{0}+\mathrm{K} \Delta \mathrm{p}\left(\underline{\overline{\mathrm{N}}}_{0}+\underline{\mathrm{N}}_{1}\right)\right]
$$

In general, the return path defined by $\overline{\mathrm{N}}_{1}$ is not known in advance. It becomes therefore necessary to compute the return path for the stresses numerically. Two techniques can be employed:

- The implicit method: it requires the resolution of a set of equations depending on the unknown variables. A highly nonlinear system is generally obtained, and consequently, the CPU time consuming increases rapidly for an increasing variables number.

- The explicit method: it consists of taking the elastic predictor as the initial condition and variables at time $t+\Delta t$ are computed by an iterative procedure. As a result, the non-linear implicit system is bypassed. However, the obtained algorithm may present convergence problems that generally can happen with Abaqus/Standard especially when using a relative important increment. To overcome this inconvenient, the following two successive actions can be planned:

- The time increment is subdivided locally (into the representative volume element RVE)

- The parameter $\mathrm{s}$ is increased from $\mathrm{s}=0.5$ to $\mathrm{s}=1$.

In this study, the explicit method is retained. Using the plastic exponential path, the rotated plastic deformation gradient is performed as

$$
\underline{\overline{\mathrm{F}}}_{1}^{\mathrm{p}}=\underline{\overline{\mathrm{F}}}_{\Delta}^{\mathrm{p}} \underline{\overline{\mathrm{F}}}_{0}^{\mathrm{p}}=\operatorname{Exp}\left(\Delta \mathrm{p} \underline{\overline{\mathrm{N}}}_{1}\right) \underline{\mathrm{F}}_{0}^{\mathrm{p}}
$$

To prove the incremental objectivity of this algorithm, we consider that the increment of deformation gradient is an arbitrarily increment of rotation (orthogonal tensor $\underline{\mathrm{F}}_{\Delta}=\underline{\mathrm{q}}_{\Delta}$ ). Figure 1 gives the incremental kinematic in this case, where $\overline{\mathrm{C}}$ denotes rotated configurations, the superscripts e and p over $\mathrm{C}$ states respectively for elastic and plastic configurations. From this figure we can write

$$
\underline{\mathrm{F}}_{1}=\underline{\mathrm{q}}_{\Delta} \underline{\mathrm{V}}_{0}^{\mathrm{e}} \underline{\mathrm{Q}}_{0} \overline{\overline{\mathrm{F}}}_{0}^{\mathrm{p}}=\underline{\mathrm{q}}_{\Delta} \underline{\mathrm{Q}}_{0} \overline{\overline{\mathrm{V}}}_{0}^{\mathrm{e}} \overline{\mathrm{F}}_{0}^{\mathrm{p}}=\underline{\mathrm{Q}}_{1} \overline{\overline{\mathrm{V}}}_{1}^{\mathrm{e}} \overline{\overline{\mathrm{F}}}_{0}^{\mathrm{p}}
$$


Thus,

$$
\underline{\mathrm{q}}_{\Delta} \underline{\mathrm{Q}}_{0} \underline{\overline{\mathrm{V}}}_{0}^{\mathrm{e}}=\underline{\mathrm{Q}}_{1} \overline{\overline{\mathrm{V}}}_{1}^{\mathrm{e}}
$$

So,

$$
\underline{\mathrm{Q}}_{1}=\underline{\mathrm{q}}_{\Delta} \underline{\mathrm{Q}}_{0} \text { and } \underline{\overline{\mathrm{V}}}_{0}^{\mathrm{e}}=\underline{\overline{\mathrm{V}}}_{1}^{\mathrm{e}}
$$

Which leads to

$$
\bar{\tau}_{1}=\bar{\tau}_{0}
$$

and

$$
\underline{\tau}_{1}=\underline{\mathrm{q}}_{\Delta} \underline{\tau}_{0} \underline{\mathrm{q}}_{\Delta}^{\mathrm{T}}
$$

Consequently, the Cauchy stress at time $t+\Delta t$ corresponds to the turned one at time $\mathrm{t}$ by $\underline{\mathrm{q}}_{\Delta}$. This property can be easily verified for the kinematic tensor $\underline{X}$ which in turn proves the incremental objectivity of the proposed incremental law.

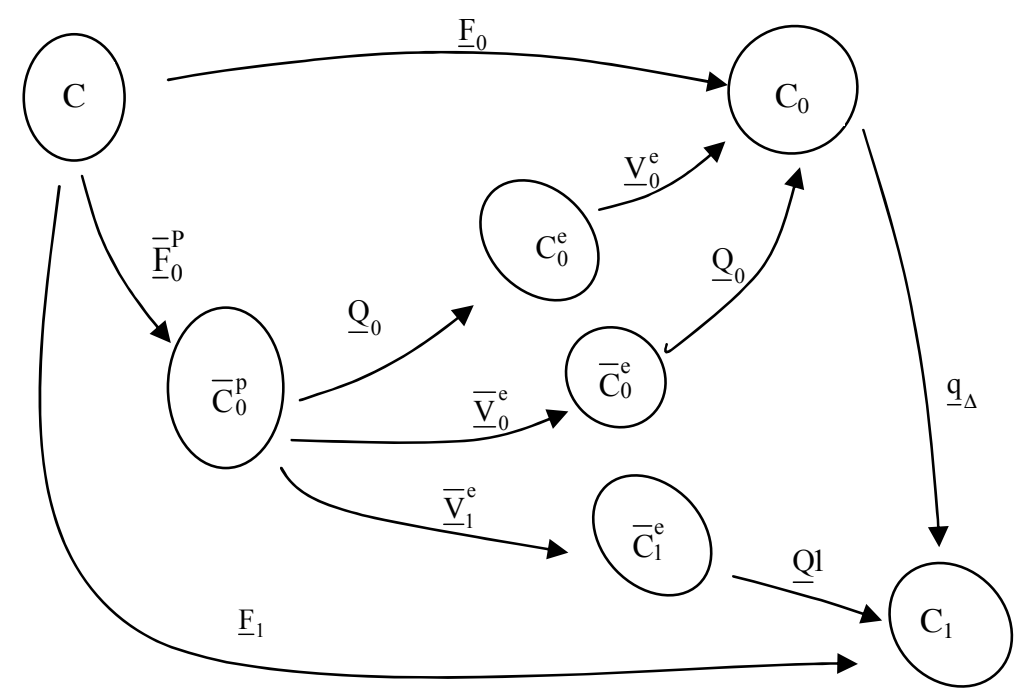

Figure 1. Incremental kinematic

The above numerical formulation was implemented into the ABAQUS-Standard (with the continuous tangent elastoplastic moduli [25]) and the ABAQUS-Explicit 
using, respectively, the implicit user subroutine UMAT and the explicit user subroutine VUMAT.

\section{Application to some sheet metal forming processes}

The main goals of the following numerical tests are, firstly, to check the accuracy of the integration algorithm, and secondly, to show that the implemented model takes into account the important aspects of isotropic and kinematic hardening.

\subsection{Application to the RVE: Parametric study of the integration algorithms}

\subsubsection{Monotonic and cyclic tension}

Stress-strain data obtained experimentally (Taherizadeh et al., 2009) will be compared with numerical results obtained by the use of the following three hardening models: (i) isotropic hardening: $\mathrm{IH}$; (ii) kinematic hardening: $\mathrm{KH}$; and (iii) combined isotropic and kinematic hardening: $\mathrm{IH}+\mathrm{KH}$. Table 1 gives the material parameters of the DP600 steel used in the following numerical simulations. A fixed time step of $\Delta \mathrm{t}=0.01 \mathrm{~s}$ was adopted. Figure 2 shows that when the isotropic hardening is only used, an increase in the axial stress is observed, and the initial flow stress level obtained from both tension and compression are equal in magnitude. In the case of the $\mathrm{KH}$ law, it is again observed an increase in the axial stress, but the magnitude of the initial flow stress level in compression path is significantly smaller than the flow stress level in tension; a clear expression of the Bauschinger effect. When the IH is combined with kinematic hardening ( $\mathrm{IH}+\mathrm{KH})$, it can be seen that there are again a clear Bauschinger effect upon strain reversal and it is clear that this model gives the best numerical results when compared with the experimental data.

Table 1. Material parameters of the DP 600 steel

\begin{tabular}{lll}
\hline \multicolumn{1}{c}{ Voce law IH } & \multicolumn{1}{c}{ Kinematic $\mathrm{KH}$} & \multicolumn{1}{c}{ Combined $(\mathrm{IH}+\mathrm{KH})$} \\
\hline $\mathrm{Q}=318 \mathrm{Mpa}$ & $\mathrm{K}=9500 \mathrm{Mpa}$ & $\mathrm{Q}=200 \mathrm{Mpa}$ \\
$\mathrm{b}=30$ & $\mathrm{~b}=30$ & $\begin{array}{l}\mathrm{K}=9500 \mathrm{Mpa} \\
\gamma=50\end{array}$ \\
& & Initial yield stress \\
\hline Hill'48 parameters & Elastic properties & $\sigma_{0}=420 \mathrm{Mpa}$ \\
$\mathrm{F}=0.438$ & $\mathrm{E}=210 \mathrm{GPa}$ & \\
$\mathrm{G}=0.462$ & $\nu=0.3$ & \\
$\mathrm{H}=0.535$ & & \\
$\mathrm{~L}=\mathrm{M}=1.5$ & & \\
$\mathrm{~N}=1.822$ & & \\
\hline
\end{tabular}




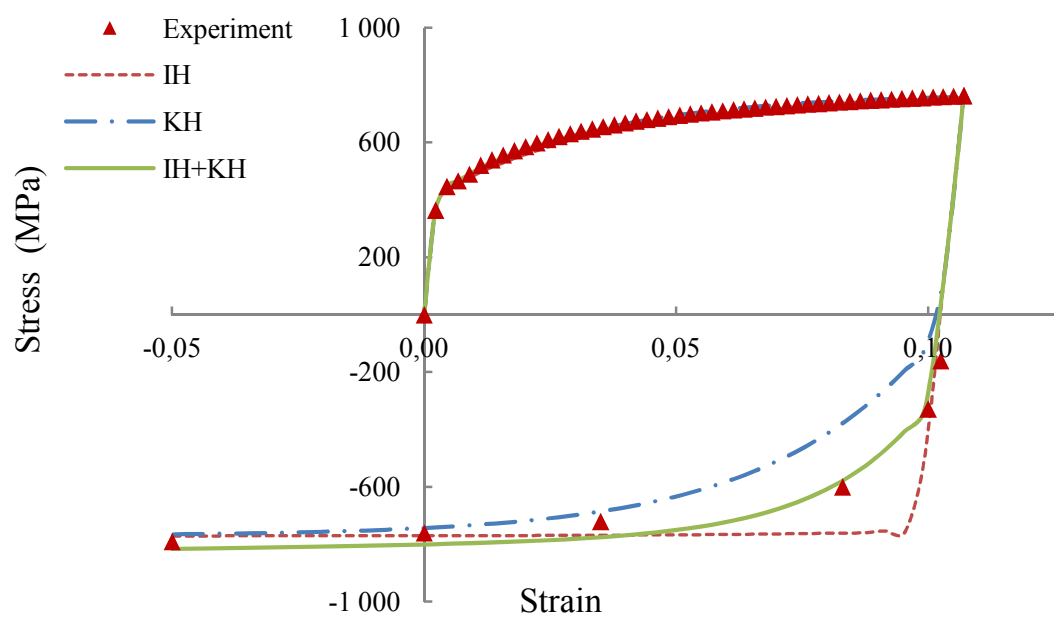

Figure 2. Comparison of axial stress versus axial strain for various hardening models in axial tension-compression test

\subsubsection{Cyclic simple shear test}

In this section, the accuracy and the stability of the integration algorithm are investigated. Also the material parameters displayed in Table 1 were used to simulate homogeneous cyclic simple shear test with an amount of shear limits of \pm 0.1 . The simulations are performed for the above three hardening models, and a model with no hardening is added, i.e, $\mathrm{Q}=0$ and $\mathrm{K}=0$.

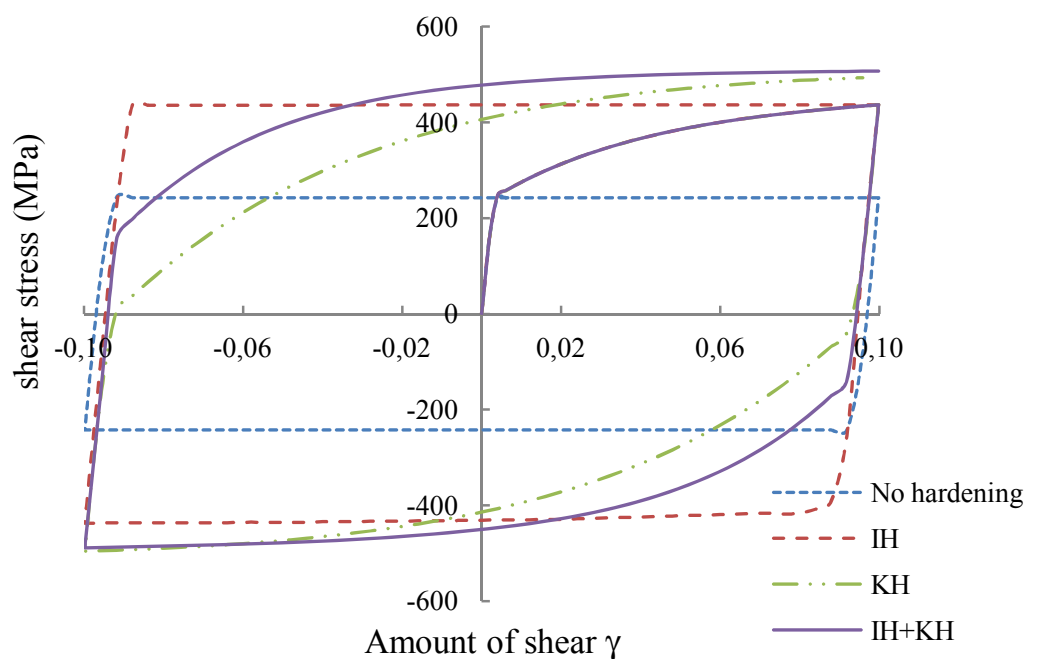

Figure 3. Shear stress versus shear strain in cyclic shear test 
Figure 3 shows the important qualitative aspects of each case in cyclic simple shear, i.e. elastic-perfectly-plastic response in the case of no hardening, a continual increase in the flow stress in cases involving isotropic hardening, and a clear Bauschinger effect in cases including kinematic hardening. In Figure 4 are plotted the numerical solutions for an increasingly shear strain increment $\Delta \gamma$. As expected, it was found that the solution accuracy decreases as the time increment increases and no stability problems were observed in the range of tested strain increments.

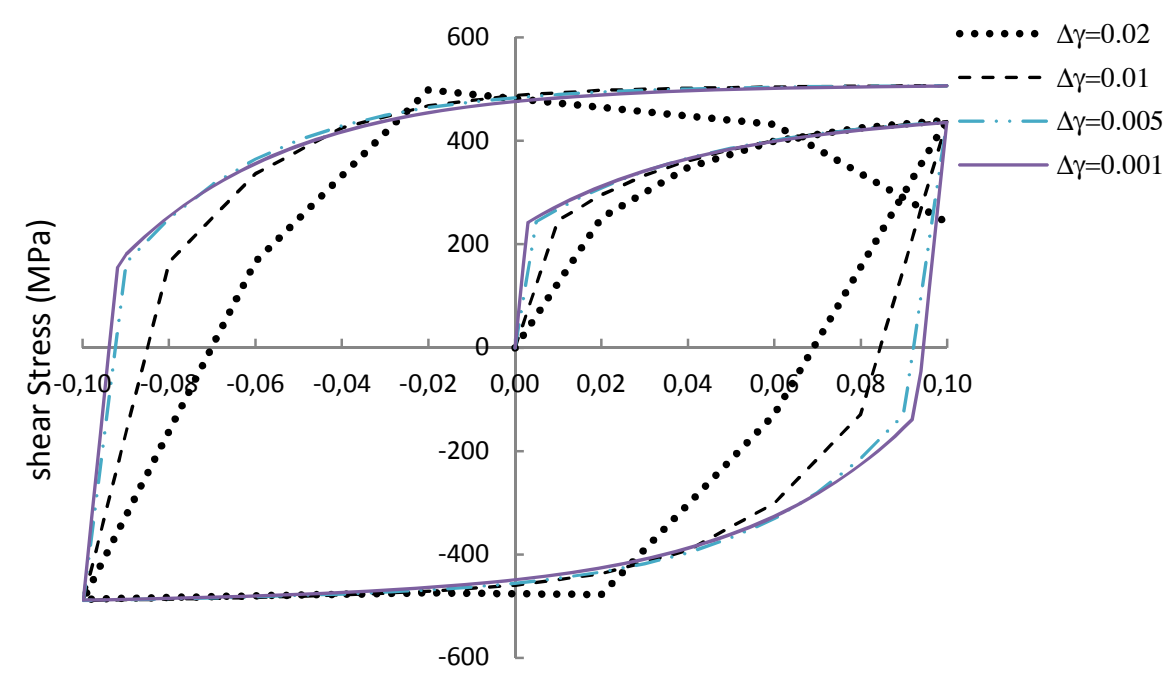

Amount of shear

Figure 4. Solutions for reversed simple shear for increasingly shear strain increments

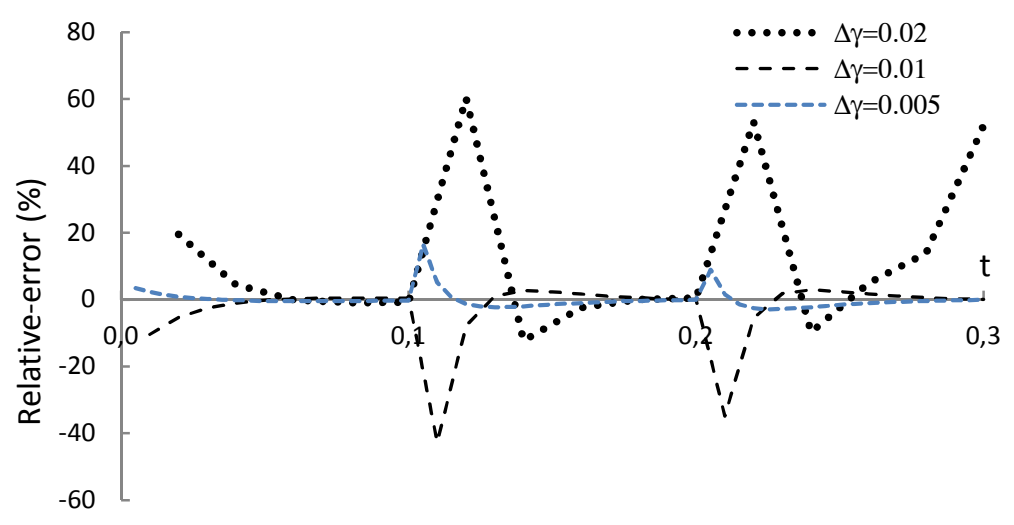

Figure 5. Solutions errors for cyclic simple shear: $t \in[0,0.1]=$ loading; $t \in[0.1,0.2]=$ unloading (reversed simple shear); $t \in[0.2,0.3]=$ reloading 
In Figure 5 are plotted a relative-error parameter based on the following shear difference

$$
\text { Relative-error (\%) }=\frac{\tau_{\text {exact }}-\tau_{\text {num }}}{\tau_{\text {exact }}} 100
$$

where $\tau_{\text {num }}$ is the numerical shear stress and $\tau_{\text {exact }}$ is the exact one. Since no exact solution is available, the solution obtained using a time step of $\Delta \gamma=10^{-3}$ was considered as the exact solution. Again, Figure 4 shows that the results accuracy decreases for increasingly time increments, especially at stress-strain reversals.

\subsection{Application to some sheet metal forming processes}

\subsubsection{Hydro bulging test}

The hydraulic bulging test is schematically represented in Figure 6. Table 2 gives the material parameters of the 2008-T4 aluminum alloy used in this test. The geometry dimensions are given as follows: blank radius of $81 \mathrm{~mm}$; die radius of 12.7 $\mathrm{mm}$ and the sheet thickness of $1.24 \mathrm{~mm}$. Note that the specific dimensions of the tools and process parameters as well as the material properties were given in (De Sousa et al., 2007; Chung and Shah, 1992). The implicit FE simulations (UMAT in Abaqus Standard) were conducted using shell elements with 5 Gauss points through the thickness direction. Only a quarter section of the specimen was considered due to the orthotropic material symmetry.

Table 2. Material parameters of 2008-T4 aluminum alloy

\begin{tabular}{ll}
\hline Voce law IH & Initial yield stress \\
$\mathrm{R}(\mathrm{p})=185+223\left(1-\mathrm{e}^{-6.14 \mathrm{p}}\right) \mathrm{MPa}$ & $\sigma_{0}=185 \mathrm{MPa}$ \\
\hline Hill'48 parameters & Elastic properties \\
$\mathrm{F}=0.764$ & $\mathrm{E}=69 \mathrm{GPa}$ \\
$\mathrm{G}=0.541$ & $\mathrm{v}=0.33$ \\
$\mathrm{H}=0.459$ & \\
$\mathrm{~L}=\mathrm{M}=\mathrm{N}=1.584$ & \\
\hline
\end{tabular}

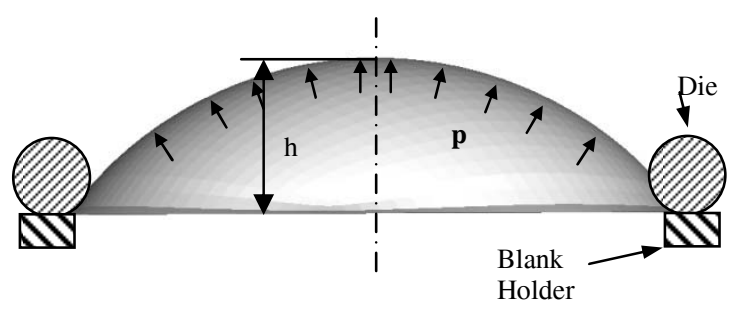

Figure 6. Schematic illustration of the hydraulic bulge test 
The deformed geometry and the equivalent plastic strain distribution are shown in Figure 7 with the final internal pressure value of $p=7 \mathrm{MPa}$. In Figure 8 are plotted the sheet thickness throughout both the roller direction (direction 1) and the transverse direction (direction 2). This figure shows that there is a slight difference between results upon these directions explained by the anisotropic nature of the material. Simulation has been also performed using the Von-Mises isotropic yield function and leads to substantially different results.

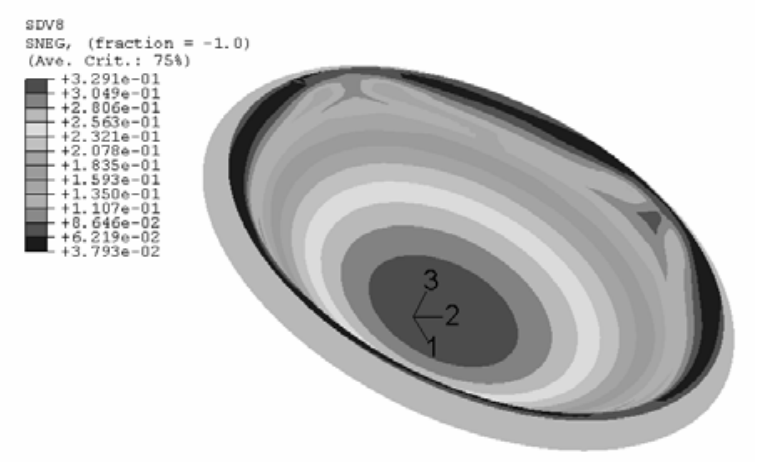

Figure 7. Deformed configuration and equivalent plastic strain distribution

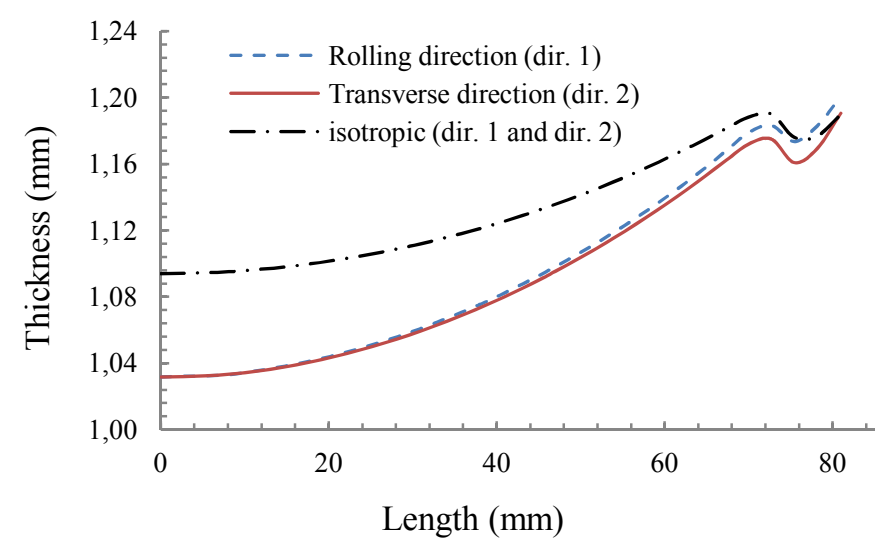

Figure 8. Thickness distribution from the pole to the outer side of the blank

In Figure 9 are plotted the measured and the predicted pressure-displacement (h) curves at the pole. It can be seen that close results are obtained when using the Hill yield criterion. Notice that a high value of the equivalent plastic strain $(0.33)$ is observed for high pressure $(\mathrm{p}>6 \mathrm{MPa})$ at the pole. As a consequence, material damage may naturally occur and can explain the difference between experimental 
and simulated results for elevated pressure values. Consequently, elastoplastic model coupled with damage should be used.

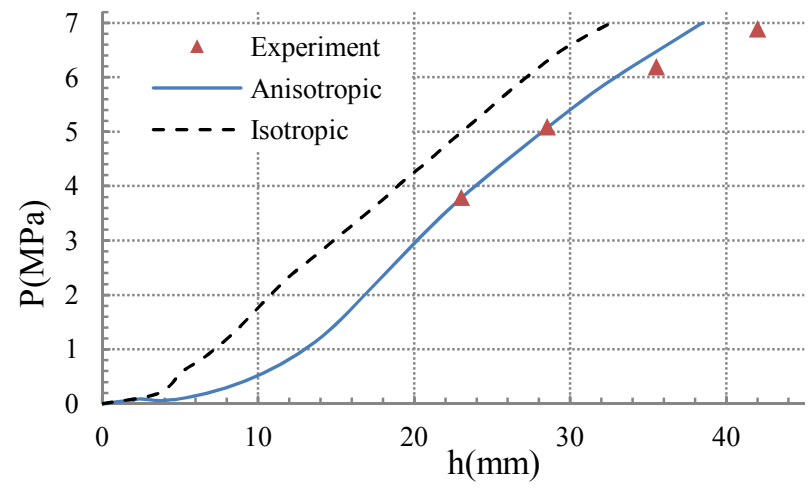

Figure 9. Polar displacement vs. hydraulic pressure

\subsubsection{Deep drawing test}

In order to experiment the implemented material model in more complicated forming processes, a cylindrical deep cup drawing is simulated. This test is schematically presented in Figure 10 and specific tool dimensions are listed in Table 3. The used material is the A12090-T3 and its parameters are displayed in Table 4.

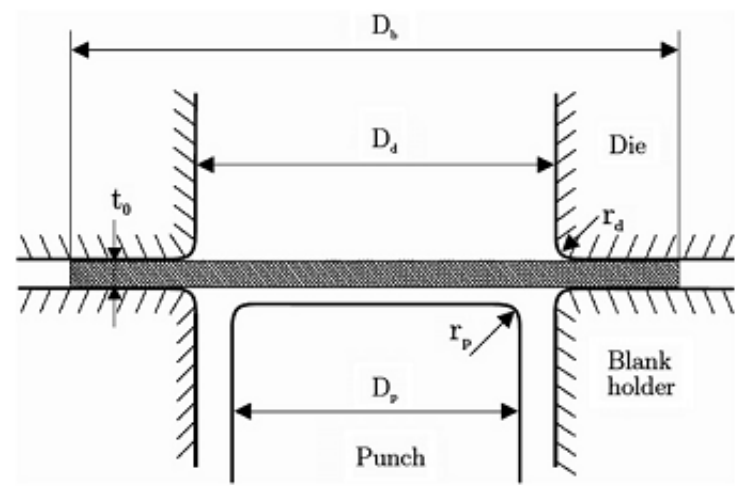

Figure 10. Cup drawing setup

Note that this test is one of the forming operations where the effects of the yielding anisotropy are most evident. After forming, the profile of the drawn cup is not uniform, but shows a series of ears. The simulations were conducted using shell element with 5 integration points through the thickness direction. Due to the material orthotropy, only a quarter section of the cup was treated. Figure 11 shows 
the finite element mesh with 456 shell elements for the quarter section of the cup. The die, punch and blank holder are all defined as rigid tools.

Table 3. Geometrical data for the cup drawing test

\begin{tabular}{ll}
\hline Punch diameter & $\mathrm{D}_{\mathrm{p}}=97.46 \mathrm{~mm}$ \\
Punch profile radius & $\mathrm{r}_{\mathrm{p}}=12.70 \mathrm{~mm}$ \\
Die opening diameter & $\mathrm{D}_{\mathrm{d}}=101.48 \mathrm{~mm}$ \\
Die profile radius & $\mathrm{r}_{\mathrm{d}}=12.70 \mathrm{~mm}$ \\
Blank diameter & $\mathrm{D}_{\mathrm{b}}=158.76 \mathrm{~mm}$ \\
Initial sheet thickness & $\mathrm{t}_{0}=1.6 \mathrm{~mm}$ \\
friction coefficient & 0.1 \\
Blank holding force & $22.2 \mathrm{KN}$ \\
\hline
\end{tabular}

Table 4. Material parameters of Al2090-T3

\begin{tabular}{ll}
\hline Isotropic law (Swift) & Kinematic law \\
\hline $\mathrm{C}=646 \mathrm{MPa}$ & $\mathrm{K}=300 \mathrm{MPa}$ \\
$\varepsilon_{0}=0.025$ & $\gamma=5$ \\
$\mathrm{n}=0.227$ & \\
\hline Hill' 48 parameters & Elastic properties \\
$\mathrm{F}=0.5702$ & $\mathrm{E}_{0}=69 \mathrm{GPa}$ \\
$\mathrm{G}=0.3632$ & $v=0.33$ \\
$\mathrm{H}=0.6368$ & Initial yield stress \\
$\mathrm{L}=\mathrm{M}=\mathrm{N}=2.57$ & $\sigma_{0}=276.6 \mathrm{MPa}$ \\
\hline
\end{tabular}

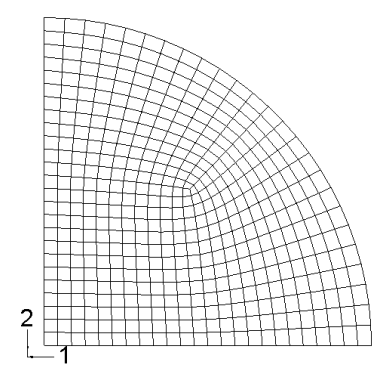

Figure 11. Element meshing of one quarter of circular sheet (1: Rolling direction; 2: Transverse direction) 
Figure 12 shows the deformed configuration of the fully drawn cup. It can be seen that four ears are obtained which agree with (Youn et al., 2000)'s results. Figure 13 shows that the thickness strain distribution in the rolling direction is in good agreement with the experimental result. However, Figure 14 shows that the thickness strain distribution in the transverse direction deviates from the simulated result at the outer side of the blank.

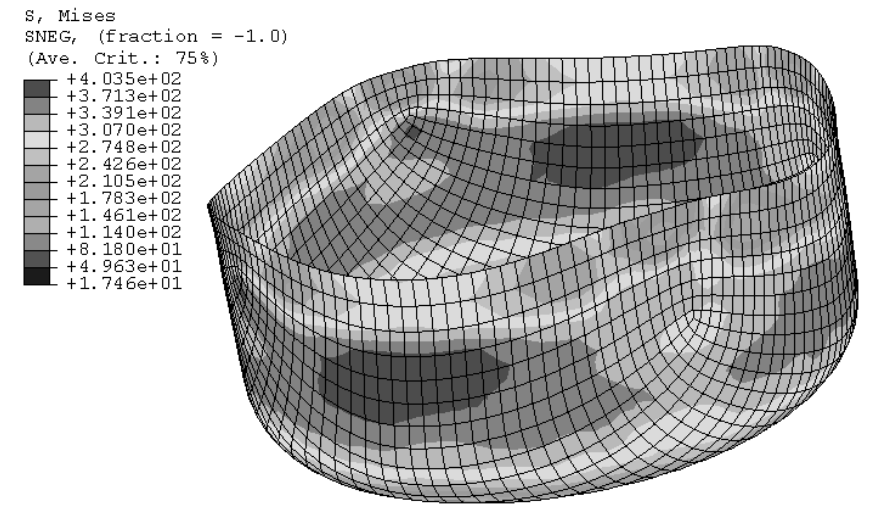

Figure 12. Deformed shape and Von-Mises stress contour of fully-drawn cup

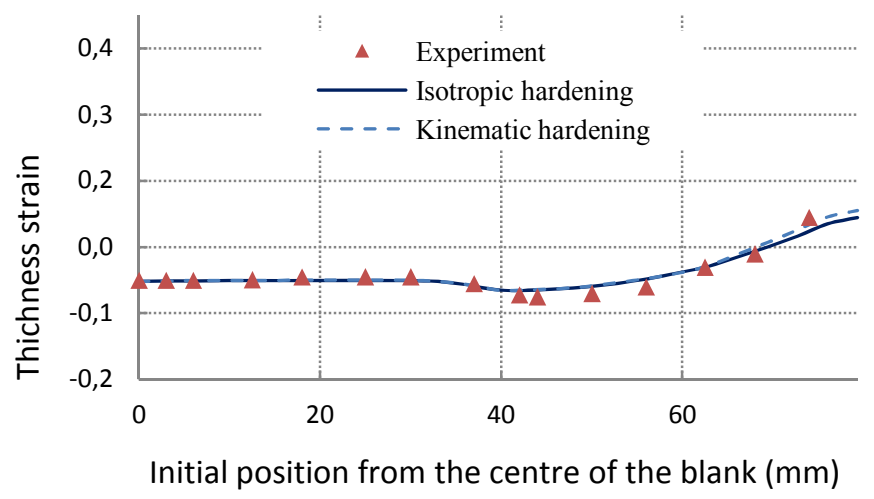

Figure 13. Thickness strain along the rolling direction

In Figure 15 are plotted the measured and the predicted cup height profiles between $0^{\circ}$ and $90^{\circ}$. This figure shows that the magnitude of the earing profile obtained numerically deviates from the experimental result, especially around $45^{\circ}$. Note that a slight improvement is observed when using the kinematic hardening. It is reported by (Yoon et al., 2000) that the prediction of both earing amplitude and location of ears depend strongly on the used yield function. As a result, usual anisotropic yield criteria are not able to provide an accurate prediction of the earing 
profile and more sophistical phenomenological yield functions can more accurately predict the earing profile.

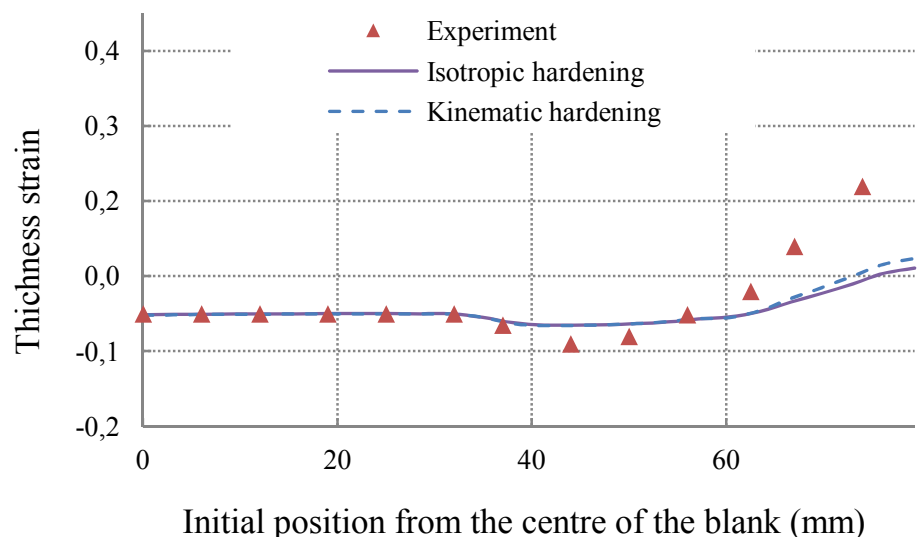

Figure 14. Thickness strain along the transverse direction

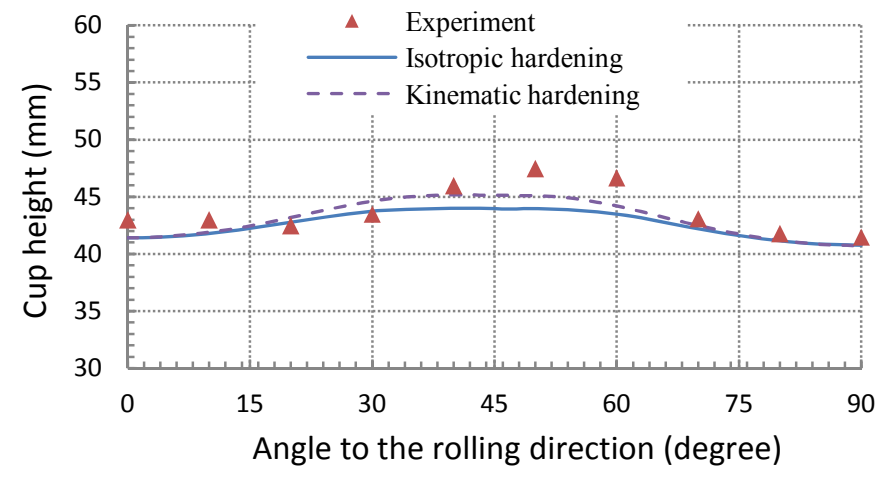

Figure 15. Influence of the hardening law on cup heights for Al2090-T3

\subsubsection{Cylindrical bending test and springback prediction}

The sheet undergoing unconstrained cylindrical bending is a benchmark example from Numisheet'02 proceeding and is schematically illustrated in Figure 16. Notice that this test has severe contact boundary conditions which can lead to numerical convergence problems (oscillatory solution). To overcome this difficulty, (Xu et al., 2004) suggested the use of a damping factor. However, the choice of this factor is arbitrarily and the accuracy of the predicted spring-backed parts is doubtful. Thus, the adopted numerical procedure is conducted with two stages. Firstly, the forming stage is analyzed using ABAQUS-Explicit and secondly the results will be imported into ABAQUS-Standard to simulate the springback stage. As justified in Section 2, 
the implemented elastic-plastic model uses the hypoelastic law [13] in forming stage, while, in springback stage, the elastic law [11] is used.

The sheet dimensions are length of $120 \mathrm{~mm}$, width of $30 \mathrm{~mm}$ and thickness of 1 $\mathrm{mm}$. The material used is the 6111-T4 aluminum alloy with material parameters given in Table 5. Notice that the specific dimensions of the tools and process parameters as well as the material proprieties were given in (Yoon et al., 2002).

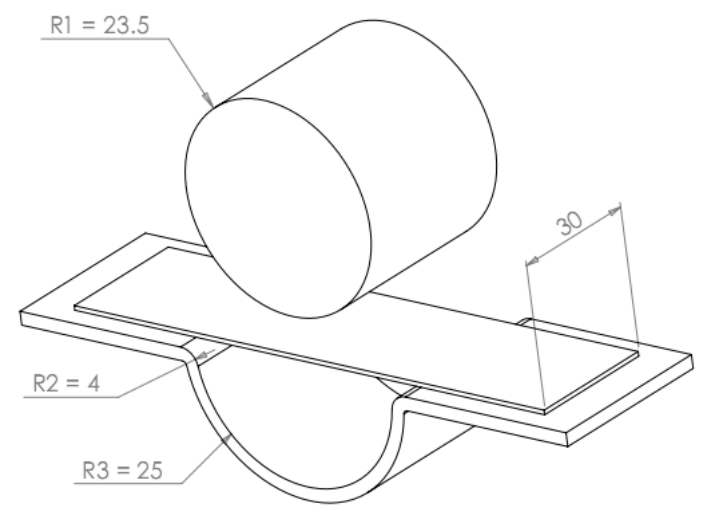

Figure 16. Problem setup and dimensions of the unconstrained cylindrical bending test

Table 5. Material parameters of the 6111-T4 aluminum alloy

\begin{tabular}{ll}
\hline Young's modulus $(\mathrm{GPa})$ & 70 \\
\hline Poisson's ration & 0.3 \\
\hline Hardening law $(\mathrm{MPa})$ & $\mathrm{R}(\mathrm{p})=192.1+237.7\left(1-\mathrm{e}^{-8.504 \mathrm{p}}\right)$ \\
\hline
\end{tabular}

Numerical simulations are carried out using plane strain elements with 4 elements through the sheet thickness. Due to the material symmetry, only a half section of the blank was analyzed. Finite element mesh used for the analysis is composed of 480 plane strain elements (CPE4R) for the half section of the blank. Figure 17 gives the equivalent stress distribution in the sheet before and after springback. Table 6 shows that significant difference is observed between the experimental springback angle and the predicted one especially when considering constant unloading elastic modulus $\left(\mathrm{E}_{0}\right)$. Notice that the angle reached just before springback stage was $32.9^{\circ}$ found by Ferreira et al. (2006) by a computer vision based method. 
Table 6. Measured and simulated springback angles

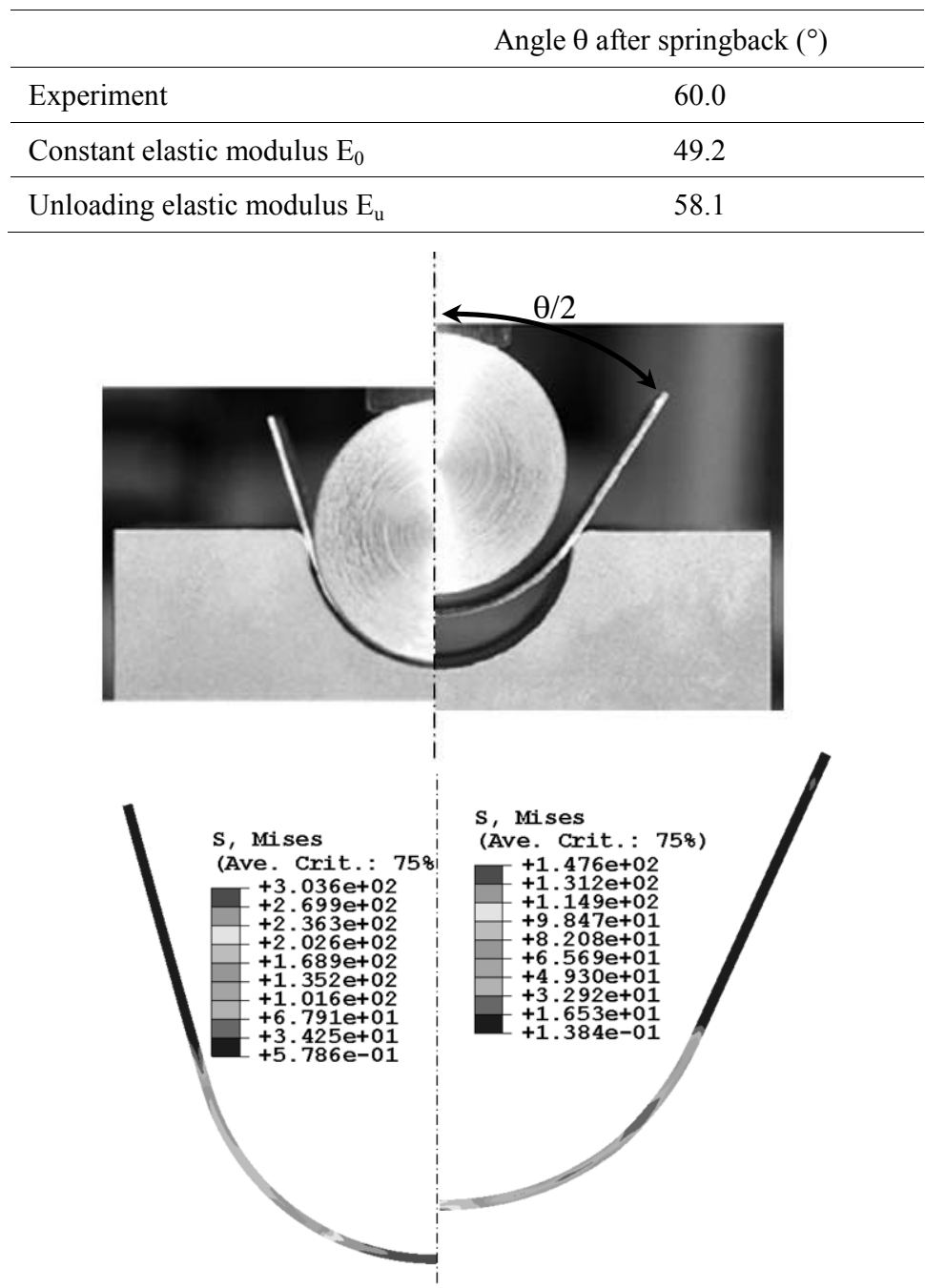

Figure 17. Stress distribution in the blank before (left) and after (right) springback

It is worth noting that the springback prediction depends on material properties. In particular, it strongly depends on the elastic domain. Many experimental investigations have revealed that the unloading elastic modulus decreases as the plastic strain increases in the material. This phenomenon is explained by the fact that there is a close relationship between the dislocations structure developed with deformation (dislocations rearrangements) and the evolution of the unloading elastic modulus. It has been also observed that this decrease saturates to a particular value 
after some amount of plastic prestrain. Both polynomial (Yu, 2009) and exponential (Yoshida et al., 2002) expressions were used in order to model this phenomenon. In this study, the widely used exponential expression is considered

$$
\mathrm{E}_{\mathrm{u}}=\mathrm{E}_{0}-\left(\mathrm{E}_{0}-\mathrm{E}_{\mathrm{a}}\right)\left[1-\exp \left(-\xi \bar{\varepsilon}_{0}^{\mathrm{p}}\right)\right]
$$

where $\mathrm{E}_{0}$ is the initial elastic modulus, $\mathrm{E}_{\mathrm{a}}$ is the decreased elastic modulus obtained for infinitely large prestrained material, $\bar{\varepsilon}_{0}^{\mathrm{p}}$ is the equivalent plastic pre-strain reached just before the unloading stage, and $\xi$ is a material constant which determines the rate of the elastic modulus decrease.

A modified formula has been proposed by (Chatti and Hermi, 2011) that gives non linear unloading behaviour (non linear recovery experimentally observed in tensile tests) in order to obtain more accurate results in springback simulations. (Cleveland and Ghosh, 2002) reported that the elastic modulus can lose $19 \%$ of its value for high strength steel and $11 \%$ for the AA6022-T4 aluminum alloy for only $7 \%$ of plastic strain. Accordingly, the unloading elastic parameters of the 6111-T4 aluminum alloy, whose properties are similar to those of AA6022-T4, are displayed in Table 7.

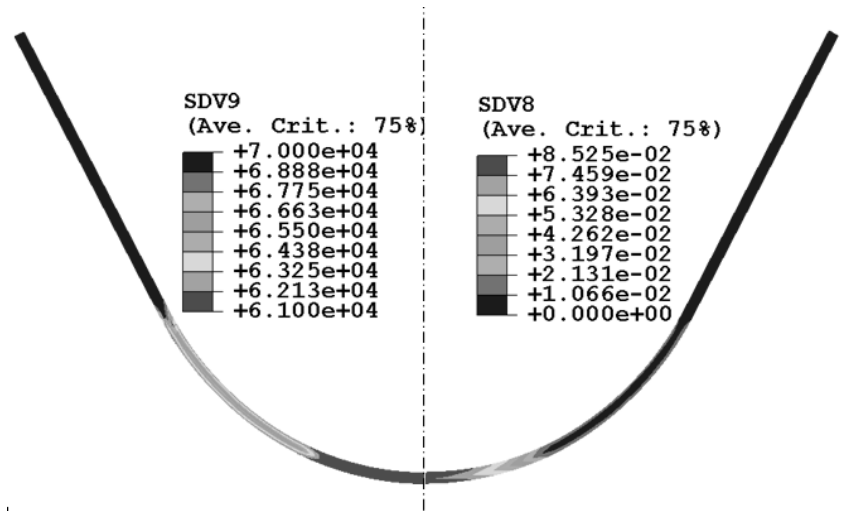

Figure 18. Distribution of the elastic modulus (left) and the equivalent plastic strain (right) in the unloaded sheet

Table 7. Properties of the unloading elastic modulus

\begin{tabular}{ccc}
\hline $\mathrm{E}_{0}$ & $\mathrm{E}_{\mathrm{a}}$ & $\xi$ \\
\hline $70 \mathrm{GPa}$ & $61 \mathrm{GPa}$ & 120 \\
\hline
\end{tabular}

In the following simulations, the elastic modulus is taken to be constant in loading phase as suggested by (Ghaei et al., 2010), whereas, in springback simulations, the unloading modulus is reduced according to Equation [47]. It can be 
easily shown that the elastoplastic tangent modulus [27] in springback simulation reduces to the elastic moduli tensor $\underline{\underline{C}}^{\mathrm{e}}$.

Figure 18 gives the elastic modulus and the equivalent plastic strain contours in the unloaded sheet. Notice that the highest value of the equivalent plastic strain is 0.085 which is generally a small value and no material damage can occur. Table 6 gives the springback angle using the unloading elastic modulus [47]. It is clear that there is a significant improvement in springback prediction when compared to the experiment. These results allow concluding that, in order to obtain accurate springback predictions in sheet metal forming processes, the elastic modulus decrease have to be considered.

\section{Conclusions and main perspectives}

The anisotropic elastoplastic behavior which accounts for non-linear isotropic/kinematic hardening under large deformations was presented. Elasticity was modeled by both:

- hypoelastic formulation used in loading phases (forming);

- elastic formulation used in elastic processes (elastic predictor or springback).

An incremental formulation was developed for the integration of the constitutive equations. In this study, only Hill's yield criterion was considered. However, the proposed integration algorithm is quite general and can be used with any yield function. User material subroutines (UMAT and VUMAT) were developed for both ABAQUS-Standard and ABAQUS-Explicit. Simulations were carried out using several hardening models. It was found that, due to its ability to model the Bauschinger effect, the combined non-linear isotropic/kinematic model gives results which agree with experiment in cyclic simple tests. The accuracy of the implemented material model was also verified through the hydraulic bulge test. However, it was found that in the cylindrical cup drawing test the numerical results slightly deviate from experimental data. Nevertheless, it would appear that numerical results can be further improved by implementing more advanced yield functions; we leave such work to the future. Finally, the unconstrained cylindrical bending of Numisheet'02 benchmark including springback was simulated by using both explicit (for loading) and implicit (for unloading) simulations. The unloading elastic modulus decrease with plastic prestrain was taken into account in the implemented model and better springback prediction was obtained. However, the hysteresis phenomenon, observed in elastic evolution (unloading/reloading), should be taken into account in the behavior law. In addition, for highly loaded parts, coupled damage model have to be taken into account in order to consider the degradation of the elastic modulus which may strongly affect springback prediction. It can be concluded that the proposed numerical algorithm is sweetable for the simulation of sheet metal forming processes including springback. 


\section{References}

Badreddine H., Saanouni K., Dogui A., "On non-associative anisotropic finite plasticity fully coupled with isotropic ductile damage for metal forming", International Journal of Plasticity, 26, 2010, p. 1541-1575.

Chatti S., Hermi N., "The effect of non-linear recovery on springback prediction", Computers and Structures, 89, 2011, p. 1367-1377.

Chatti S., "Effect of the elasticity formulation in finite strain on springback prediction", Computers and Structures, 88, 2010, p. 796-805.

Chatti S., Dogui A., Dubujet P., Sidoroff F., “An objective incremental formulation for the solution of anisotropic elastoplastic problems at finite strain", Communication in Num. Methods in Engeneering, 17, 2010, p. 845-862.

Chung K., Shah K., "Finite element simulation of sheet metal forming for planar anisotropic metals", International Journal of Plasticity, 8, 1992, p. 453-476.

Cleveland R.M., Ghosh A. K., "Inelastic effects on springback in metals", International Journal of Plasticity, 18, 2002, p. 769-785.

De Sousa R.J. A., Yoon J.W., Cardoso R. P. R., Valente R. A. F., Gràcio J.J., "On the use of a reduced enhanced solid-shell (RESS) element for sheet forming simulations", International Journal of Plasticity, 23, 2007, p. 490-515.

Dogui A., «Cinématique bidimensionnelle en grandes déformations - Application à la traction hors axes et à la torsion », Journal de Mécanique Théorique et Appliquée, 7, 1988, p. 43-64.

Ferreira J.A., Sun P., Grácio J.J., "Close loop control of a hydraulic press for springback analysis", Journal of Materials Processing Technology, 177, 2006, p. 377-381.

Ghaei A., Green D.E., Taherizadeh A., Semi-implicit numerical integration of YoshidaUemori two-surface plasticity model, International Journal of Mechanical Sciences, 52, 2010, p. 531-540.

Huges T.J.R., Winget T. J., "Finite rotation effects in numerical integration of rate constitutive equations arising in large-deformation analysis", Int. J. for Numer. Meth. in Eng., 15, 1980, p. 1862-1867.

Ingarao G., Di Lorenzo R., “A new progressive design methodology for complex sheet metal stamping operations: Coupling spatially differentiated restraining forces approach and multi-objective optimization", Computers and Structures, 88, 2010, p. 625-638.

Laurent H., Grèze R., Oliveira M. C., Menezes L. F., Manach P.Y., Alves J. L., "Numerical study of springback using the split-ring test for an AA5754 aluminum alloy", Finite Elements in Analysis and Design, 46, 2010, p. 751-759.

Lemaître J., Chaboche J.L., Mécanique des matériaux solides, Dunod Eds, Paris, 1985.

Mandel J., «Equations constitutives et directeurs dans les milieux plastiques et viscoplastiques », International Journal of solids and structures, 9, 1971, p. 725-740. 
Nagtegaal J. C., Dejong J.E., "Some computational aspects of elastic-plastic large strain analysis", International journal of numerical methods in engineering, 17, 1981, p. 15-41.

Ortiz M., Simo J.C., "An analysis of a new class of integration algorithms for elastoplastic relations", International Journal of Numerical Methods in Engineering, 23, 1986.

Ortiz R., Popov E.P., "Accuracy and stability of integration algorithms for elastoplastic constitutive relations", International Journal for numerical methods and engineering, 21, 1985, p. 1561-1576.

Sidoroff F., Dogui A., "Some issues about anisotropic elastic-plastic models at finite strain", International Journal of solids and structures, 38, 2001, p. 9569-9578.

Sidoroff F., "Lois incrémentales en MMC grandes déformations », $10^{e}$ Congrés Français de Mécanique, Paris, septembre, 1991.

Taherizadeh A., Green D. E., Ghaei A., Yoon J.W., "A non-associated constitutive model with mixed iso-kinematic hardening for finite element simulation of sheet metal forming", International Journal of Plasticity 26, 2009, p. 288-309.

Xu W.L., C. H. Ma, C.H. Li and W.J. Feng, "Sensitive factors in springback simulation for sheet metal forming", Journal of Materials Processing Technology, 151, 2004, p. $217-$ 222.

Yoon J.W., Pourboghrat F., Chung K., Yang D.Y., Springback prediction for sheet metal forming process using a 3D hybrid membrane/shell method, International Journal of Mechanical Sciences, 44, 2002, p. 2133-2153.

Yoon J.W., Barlat F., Chung K., Pourboghrat F., Yangn D.Y., "Earing predictions based on asymmetric non-quadratic yield function", International Journal of Plasticity, 16, 2000, p. $1075-1104$.

Yoshida F., Uemori T., Fujiwara K., "Elastic-plastic behavior of steel sheets under in-plane cyclic tension-compression at large strain", International Journal of Plasticity, 18, 2002, p. 633-659.

Yu H. Y., "Variation of elastic modulus during plastic deformation and its influence on springback", Materials and Design, 30, 2009, p. 846-850.

Received: 28 April 2011

Accepted: 6 January 2012 
